\title{
Omega-3 polyunsaturated fatty acids: photoprotective macronutrients
}

\author{
Suzanne M Pilkington ${ }^{1}$, Rachel EB Watson ${ }^{1}$, Anna Nicolaou ${ }^{2}$ and Lesley E Rhodes ${ }^{1}$
}

${ }^{1}$ Dermatological Sciences, Inflammation Sciences Research Group, School of Translational Medicine, University of Manchester, Manchester Academic Health Science Centre, Salford Royal NHS Foundation Hospital, Manchester, UK; ${ }^{2}$ School of Pharmacy and Centre for Skin Sciences, School of Life Sciences, University of Bradford, Bradford, UK

Correspondence: Professor L E Rhodes, Photobiology Unit, Dermatological Sciences, Salford Royal NHS Foundation Hospital, Manchester M6 8HD, UK, Tel.: 44-161-206-1150, Fax: 44-161-206-1156, e-mail: lesley.e.rhodes@manchester.ac.uk

Abstract: Ultraviolet radiation (UVR) in sunlight has deleterious effects on skin, while behavioural changes have resulted in people gaining more sun exposure. The clinical impact includes a yearon-year increase in skin cancer incidence, and topical sunscreens alone provide an inadequate measure to combat overexposure to UVR. Novel methods of photoprotection are being targeted as additional measures, with growing interest in the potential for systemic photoprotection through naturally sourced nutrients. Omega-3 polyunsaturated fatty acids (n-3 PUFA) are promising candidates, showing potential to protect the skin from UVR injury through a range of mechanisms. In this review, we discuss the biological actions of $n-3$ PUFA in the context of skin protection from acute and chronic UVR overexposure and describe how emerging new technologies such as nutrigenomics and lipidomics assist our understanding of the contribution of such nutrients to skin health.

Key words: lipidomics - nutrigenomics - omega-3 polyunsaturated fatty acids - photoprotection - ultraviolet radiation

Accepted for publication 25 March 2011

\section{Introduction}

Utilisation of bioactive nutrients for enhancement of skin health is a novel area of research. Macronutrients such as omega-3 polyunsaturated fatty acids (n-3 PUFA) are attracting attention as potential agents for maintenance of skin health and treatment of skin disorders, particularly those mediated by solar ultraviolet radiation (UVR), including sunburn, cancer, photosensitivity and photoageing (1). Skin cancers are now the commonest cancers in many white-skinned populations, and their incidence continues to rise (2). Moreover, there is increasing public awareness that most visible signs of skin ageing on exposed sites are attributable to UVR, i.e. photoageing. Eicosapentaenoic acid (EPA, 20:5n-3) is a longchain (LC) n-3 PUFA reported to protect the skin against deleterious UVR effects, reducing UVR-induced inflammation (3-5) and indicators of photoageing and photocarcinogenesis (6-9). Omega3 PUFA are multi-active agents that may convey photoprotection through a range of mechanisms including alterations in membrane fluidity, modification of signal transduction, transcription factor activation, modulation of oxidative stress, and production of bioactive lipid mediators. While research continues into mechanisms underlying the protective effects of LC n-3 PUFA, interest is developing into the potential effects of short-chain (SC) n-3 PUFA, such as $\alpha$-linolenic (ALA, 18:3n-3) and stearidonic (STA, 18:4n-3) acids, also found in the human diet (10).

In this article, we review the state of knowledge of cutaneous n-3 PUFA biology, and the nature and mechanisms of their reported photoprotective properties. We also evaluate how the new technologies of lipidomics and nutrigenomics may further understanding of the complex relationships between UVR, cell signalling and gene expression, and their modification by n-3 PUFA.

\section{Topical photoprotection - is it enough?}

Human exposure to UVR has increased over the past 50 years, and this is largely attributable to behavioural changes relating to sun exposure, including travel to sunny holiday locations, with use of sunbeds and depletion of the stratospheric ozone contributing (11). In the future, global warming may also play a role, with warmer climates encouraging people to spend more of their leisure time outdoors $(11,12)$. Recommended strategies for protecting skin against deleterious UVR effects include covering with clothing, avoiding midday sun, seeking shade, and topical application of sunscreens (13-16). Topical sunscreens reduce UVR effects by scattering, reflecting or absorbing radiation. However, in practice, sunscreens are not applied as thickly or evenly as in the manufacturers' test procedures; therefore, the anticipated protection factor is not reached (17-19). This may result in a false impression of the degree of protection and then increased time spent outdoors (20). Furthermore, a significant proportion of an individual's annual UVR exposure occurs during routine (nonholiday) activities when topical sunscreens are not typically used $(21,22)$. While topical sunscreens can provide a high sun protection factor (SPF) against acute UVR-induced erythema, i.e. sunburn, nutrients may provide a lower level of protection against chronic, repeated UVR insults; hence, a combined approach may be optimal. Dietary nutrients acting within skin cells to modulate biological responses to UVR could provide a safe and continuous systemic approach to UVR protection, additional to the use of physical measures $(9,23)$.

\section{How are n-3 PUFA obtained?}

Omega-3 and n-6 PUFA are regarded as essential fatty acids (EFA); human metabolism requires a dietary supply of the parent linoleic (LA, 18:2n-6) and $\alpha$-linolenic (ALA;18:3n-3) acids, as well 
as some elongated and desaturated LC-PUFA including EPA and docosahexaenoic (DHA, 22:6n-3). The richest dietary sources of EPA and DHA are marine animals, with oily fish such as mackerel, sardines, herrings, and salmon containing EPA and DHA at $30-50 \%$ of tissue fatty acids (24). Negative aspects of encouraging oily fish consumption are overfishing of wild stocks and health concerns regarding heavy metal contamination and polychlorinated biphenyls (PCBs) $(25,26)$. Potential solutions are the availability of distilled n-3 PUFA supplements, and new developments in biotechnology allowing LC n-3 PUFA enrichment of oilseed crops and micro-organisms (27). Insertion of genes encoding metabolic machinery of the n-3 pathways into the plant Arabidopsis thaliana has shown promising results, with LC n-3 PUFA reaching up to $5 \%$ of total seed fatty acids $(28,29)$.

In contrast, SC n-3 PUFA ALA and STA are commonly found in plants and plant seed oils. The fatty acid composition of any particular food source can vary considerably and values tend to differ between reports; however, linseed, canola (rapeseed) and soyabean oils are regarded as some of the richest sources of ALA available for human consumption, containing $\sim 53.3,11.1$ and $6.8 \%$ ALA, respectively (30). ALA is also present in walnuts and butternuts, at $\sim 6.8 \%$ and $8.7 \%$, and in smaller quantities $(0.1-$ $1.7 \%$ ) in several other edible plants including raspberries, lettuce and peas. Sources of STA are more limited: blackcurrant seed oil contains $\sim 3 \%$ STA, while plants of the Boraginaceae family are among the richest natural sources (31), with Echium plantagineum seed lipids containing $\sim 13 \%$ STA (24). Echium oil-based STArich supplements are now marketed as vegetarian equivalents of fish oil-rich supplements, with claims of health benefits in skin (32), although published data are lacking. Genetic modification of crops has developed strains of the canola plant producing seed oils with STA levels up to $23 \%$ (33), and marine algae is another potential STA source (31).

The average daily intake of n-3 PUFA varies geographically, but in the West is typically quite low in the present day. A survey of the dietary habits of 1724 British adults over a 7-day period revealed a daily intake of 1.7-2.0 g of n-3 PUFA and 9.4-12.9 $\mathrm{g}$ of n-6 PUFA (34). In a study of 4884 French adults, n-3 and n-6 PUFA levels were similar to those in the UK at $1.14-1.44 \mathrm{~g} /$ day and $8.25-10.84 \mathrm{~g} /$ day, respectively (35). However, there is evidence that historically the amounts of n-3 PUFA and n-6 PUFA in the diet were balanced, i.e. with a ratio of 1:1 and with higher intakes of n-3 PUFA (36). This is proposed to be a more healthy diet than the typical Western intake that is heavily skewed towards n-6 PUFA, as in general the mediators derived from n-3 PUFA moderate the effects of the more potent, pro-inflammatory n-6 PUFA-derived mediators (36).

\section{Short- vs long-chain n-3 PUFA}

Parent n-3 PUFA ALA is metabolised to EPA and DHA via a series of elongation and desaturation reactions (Fig. 1). Human epidermis displays low $\Delta 5$ and $\Delta 6$ desaturase activity, and the LC forms require synthesis elsewhere, primarily in the liver, with delivery to skin through the circulation (37). However, conversion of dietary ALA to LC n-3 PUFA is relatively inefficient in mammals with only about $0.2 \%$ of plasma ALA converting to EPA (38), while the majority of dietary ALA undergoes $\beta$-oxidation for energy production (39). Several factors can influence this metabolic pathway including dietary levels of n-6 and n-3 PUFA (40).

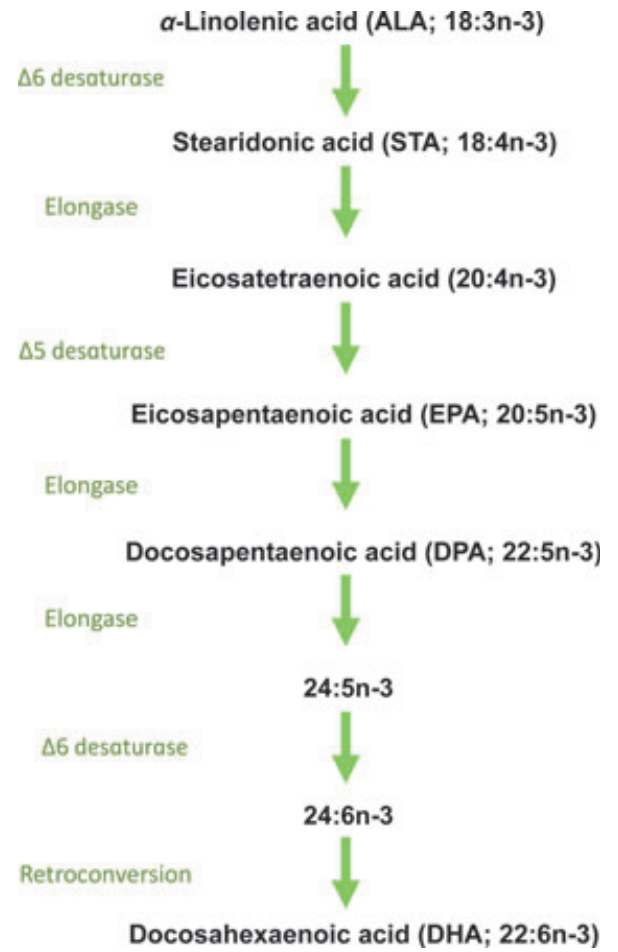

Figure 1. Conversion of the short-chain Omega-3 polyunsaturated fatty acids ( $n-3$ PUFA) ALA, via stearidonic acid, to long-chain n-3-PUFA, Eicosapentaenoic acid and docosahexaenoic.

Dietary ALA supplementation substantially increases skin phospholipid content of ALA in rodents, where it is suggested to play an active role in skin barrier function $(10,41)$. Whether ALA accumulates in human skin in a similar manner is unclear. Stearidonic acid may act as an alternative source of EPA, bypassing the need for $\Delta 6$ desaturation of ALA. This SC n-3 PUFA acid can be directly elongated to eicosatetraenoic acid (ETA; 20:4n-3) and subsequently desaturated to EPA (Fig. 1). Although dependency on $\Delta 5$ desaturase may inhibit STA metabolism to EPA in the skin, STA could still prove more successful than ALA as a LC PUFA source. In red blood cells and plasma phospholipids, STA was approximately 2-fold more effective in increasing EPA levels than ALA (42,43). Interestingly, recent studies in hairless mice and human skin $(44,45)$ showed that topical eicosatrienoic acid (20:3n-3) offered significant protection against UV-induced skin thickening, inflammatory cell infiltrate and transepidermal water loss (45).

While further evaluation of the application and impact of SC n-3 PUFA on the skin is required, currently the most favourable method of elevating cutaneous LC n-3 PUFA is by increasing dietary EPA content. In general, n-3 PUFA levels in human skin are very low, i.e. $<2 \%$ of total epidermal fatty acids, but this has been demonstrated to be significantly increased following dietary LC n-3 PUFA supplementation $(3,7)$. In a human study, a 3-month course of $4 \mathrm{~g}$ EPA daily resulted in skin EPA levels increasing 8 -fold (7). Topical application of EPA to the skin is also possible, although the relative bioavailability that can be achieved with this method is uncertain. 


\section{Cutaneous eicosanoids and other PUFA-derived mediators}

Arachidonic acid (AA, 20:4n-6) and EPA are esterified in epidermal phospholipids, and released by phospholipase $A_{2}\left(\mathrm{PLA}_{2}\right)$ isoforms, which are upregulated by UVR (46-48). Once released, AA and EPA compete for metabolism by cutaneous cyclooxygenases (COX) and lipoxygenases (LOX) to produce eicosanoids, including prostaglandins (PG), thromboxanes, leukotrienes, mono- and poly-hydroxy fatty acids and lipoxins (49). These extracellular lipid-signalling molecules are involved in the regulation of various cellular processes during normal homoeostasis and also play key roles during skin inflammation and tumorigenesis (49-52). Cyclooxygenase metabolism of EPA produces prostaglandins of the 3-series, e.g. $\mathrm{PGD}_{3}, \mathrm{PGE}_{3}$ and $\mathrm{PGF}_{3 \alpha}$, whereas $\mathrm{LOX}$ enzymes transform EPA to hydroxyeicosapentaenoic acids (HEPE) and 5-series leukotrienes (Fig. 2). Metabolism of AA by these enzymes produces 2-series prostaglandins $\left(\mathrm{PGD}_{2}, \mathrm{PGE}_{2}\right.$ and $\mathrm{PGF}_{2 \alpha}$ ), hydroxyeicosatetraenoic acids (HETE) and 4-series leukotrienes (Fig. 2) (50,53). EPA-derived eicosanoids appear less potent than their AA-derived counterparts and tend to either act as agonists or dilute the pro-inflammatory effects of the latter (54-56). Docosahexaenoic acid can also be metabolised to a range of lipid mediators in the skin including 17-hydroxydocosahexaenoic acid (17-HoDHE), thought to be anti-inflammatory (57). Finally, a number of n-3 and n-6 cutaneous PUFA can also be metabolised by cytochrome (CYP) P450 enzymes or undergo nonenzymatic oxidation, producing an even wider variety of mediators and potential biological effects (58).

\section{Omega-3 PUFA as regulators of transcription}

Physiological effects observed as a result of changes in membrane LC-PUFA composition have been understood to be because of altered membrane fluidity and n-3/n-6 PUFA-derived eicosanoid ratios. However, LC-PUFA also modulate nuclear transcription factors such as nuclear factor- $\kappa \mathrm{B}(\mathrm{NF}-\kappa \mathrm{B})$, activator protein-1 (AP-1) and sterol regulatory element-binding proteins (SREBP), and receptors such as peroxisome proliferator-activated receptors (PPAR), retinoid X receptors (RXR) and liver X receptors (LXR), all of which regulate genes concerned with lipid metabolism and inflammation $(59,60)$. The influence of n-3 PUFA on their activity

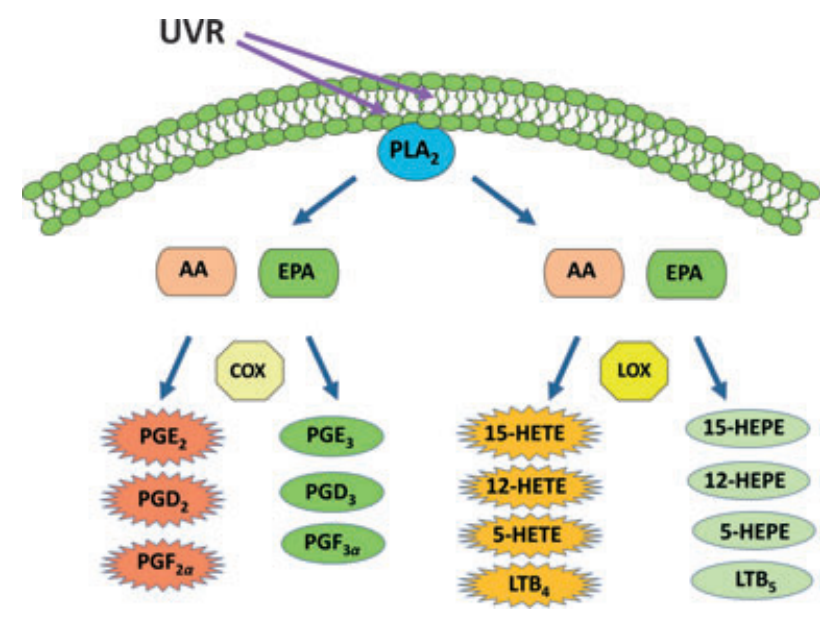

Figure 2. Metabolism of Eicosapentaenoic acid and AA to eicosanoids by COX and lipoxygenases enzymes. differs according to tissue, and, to date, few studies have assessed the impact of these fatty acids on UVR-induced transcriptional regulation in human skin.

\section{PPAR}

Both n-3 PUFA and PG are able to stimulate PPAR to bind to peroxisome proliferator response elements (PPRE) in gene promoter regions, regulating gene expression. PPAR- $\gamma$ activity is upregulated by UVR in normal primary human keratinocytes (NPHK), in association with increased COX-2 expression and $\mathrm{PGE}_{2}$ synthesis, which is partially inhibited by PPAR- $\gamma$ antagonists (61). UVR is proposed to increase PPAR- $\gamma$ activity via generation of free radicals that oxidise glycerophosphocholines (GPC) forming 1-hexadecyl 2-azalaoyl phosphatidylcholine (azPC), a potent PPAR- $\gamma$ agonist (62). Using HaCat keratinocytes, Chêne et al. (63) showed that both EPA and $\gamma$-linolenic acid (GLA, 18:3n-6) upregulated COX-2 expression via PPAR- $\gamma$. In contrast, PPAR- $\alpha$ and PPAR- $\beta$ are downregulated by UVB in human skin and are associated with reduced inflammation when activated by synthetic agonists (64). Currently, it remains unclear whether some antiinflammatory effects of LC n-3 PUFA in the skin are mediated through regulation of PPAR signalling pathways.

\section{NF-kB}

Nuclear factor- $\kappa \mathrm{B}$ is an important transcription factor involved in epidermal homoeostasis and is upregulated in response to UVR and oxidative stress (Fig. 3) (65,66). It regulates expression of many genes involved in inflammation including pro-inflammatory cytokines such as TNF- $\alpha$, IL-1 $\alpha$, IL-1 $\beta$, IL-6 and IL-8 (67). A role for NF-kB in regulating cell proliferation has also been demonstrated in transgenic mice, where repression of NF-kB increased keratinocyte proliferation and epidermal hyperplasia (68). Jin et al. (45) reported increased NFkB activity in hairless mouse skin after UVB irradiation. They also found that LC n-3-PUFA, eicosatrienoic acid, was capable of decreasing UV-induced NF-kB activation in association with reduced IL- $1 \beta, \mathrm{COX}-2$ and MMP-13 (the major collagenase in the murine system), suggesting n-3 PUFA may repress expression of these proteins via regulation of the NF-kB signalling pathway (45). This suppression of NF-kB activation by n-3 PUFA may result from inhibition of IkB phosphorylation (Fig. 3) (69). Interestingly, fish oil increased the expression of antioxidant enzyme genes, manganese-super oxide dismutase (Mn-SOD) and glutathione-S-transferase (GST) by up to 4-fold in the liver, while decreasing expression of genes involved in ROS generation (70). Therefore, n-3 PUFA may inhibit NF-kB-mediated gene expression through a reduction in oxidative stress. We speculate that n-3 PUFA may modulate the expression of oxidative stress responsive enzymes in the skin, as has been reported for carotenoid antioxidants (71).

\section{AP-1}

Ultraviolet radiation may activate cell surface receptors directly, behaving as a ligand, or indirectly through generation of ROS, and subsequently this stimulates expression and DNA binding of transcription factor AP-1 through mitogen-activated kinase (MAPK) signalling (Fig. 3) (65,72,73). AP-1 is a heterodimer, composed of c-Fos and c-Jun subunits, which binds to response elements in promoter regions of genes involved in proliferation, metastasis and cellular metabolism; therefore, aberrant AP-1 activity is often observed in tumors (74). In humans, non-UVRexposed skin constitutively expresses c-Fos with Jun-D being its 


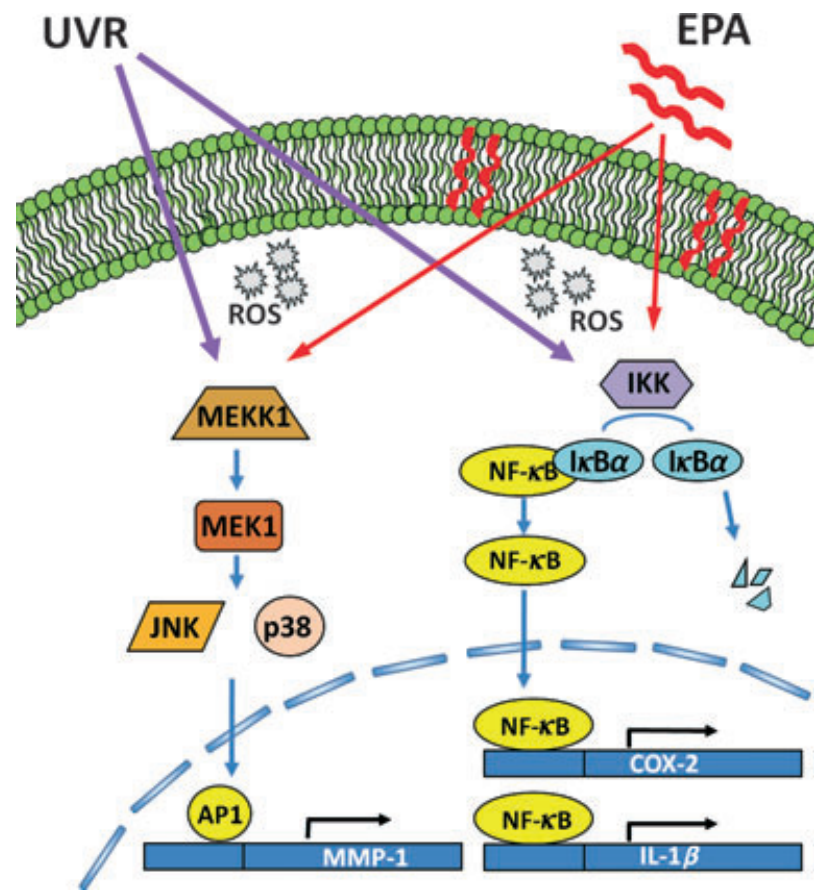

Figure 3. Hypothesised action of Omega-3 polyunsaturated fatty acids (n-3 PUFA) on UVR-induced $\mathrm{NF} \kappa \mathrm{B}$ and activator protein-1 signalling in skin. The influence of the environmental agent, UVR, can be modified at several levels by an increased dietary intake of n-3 PUFA. This includes reduced UVR activation of specific receptor-activated kinase pathways, potentially through alteration of plasma membrane fluidity and/or modulation of oxidative stress. Consequently, downstream signalling pathways are not activated, preventing translocation of transcription factors to the nucleus and thus induction of gene expression.

major binding partner. However, on UV exposure, c-Jun is quickly upregulated and actively competes with Jun-D to produce a more effective transcription factor (73). In a mouse epidermal cell line, Liu et al. (75) demonstrated that DHA and EPA, but not $\mathrm{AA}$, were effective at inhibiting cellular transformation via a reduction in AP-1 activity. This study supports previous research indicating that the ratio of dietary $n-3 / n-6$ PUFA is an important factor in the development of skin cancer. Moreover, AP-1 is implicated in photoageing (76), as discussed in the following section.

\section{Omega-3 PUFA and photoprotection}

The therapeutic potential of n-3 PUFA in photoprotection is summarised in Table 1.

\section{The sunburn response}

Induced by acute overexposure to UVR, this is an inflammatory reaction characterised clinically by erythema and oedema, and histologically by thickening of the stratum corneum, apoptotic epidermal cells ('sunburn cells') and dermal leucocytic infiltration (77-79). These acute responses are regulated via a network of cellsignalling pathways that are upregulated in the skin following UVR. A pathway of pivotal importance in inflammation production is the metabolism of AA by COX-2, producing pro-inflammatory lipid mediators (80). Ultraviolet radiation is known to both activate $\mathrm{PLA}_{2}$, triggering release of PUFA from the cell membrane and upregulate fatty acid-metabolising enzymes including inducible COX (COX-2) and LOX (81). Recent data suggest UVR may also enhance the skin's prostanoid levels by inhibiting their breakdown $(82,83)$. Increased concentrations of pro-inflammatory eicosanoids are seen in the skin, including $\mathrm{PGE}_{2}$ and a range of HETE, which contribute to regulation of vasodilatation and leucocyte infiltration, respectively $(51,84)$. Elevated EPA levels compete with AA for metabolism, reducing production of AA-derived mediators involved in UV inflammation. These anti-inflammatory effects have been demonstrated in human studies following supplemental fish oil (1.8 g EPA + 1.2 g DHA), where UV erythemal sensitivity was significantly reduced $(4,85)$ in association with an increase in cutaneous $n-3 / n-6$ PUFA ratio and $>60 \%$ reduction in UV-induced skin $\mathrm{PGE}_{2}$ levels $(3,4)$. Photoprotective effects of n-3 PUFA were confirmed in a double-blind randomised study in healthy volunteers using $4 \mathrm{~g}$ of purified (95\%) EPA supplements; $\%$ EPA/total fatty acids in epidermal phospholipids increased 8 -fold and the minimal erythemal dose (MED) increased by $36 \%$ (7). Systemic delivery of n-3 PUFA ALA has also shown some UVR protection in hairless mice, reducing erythema in association with reduced $\mathrm{PGE}_{2}$ (10). Cutaneous levels of EPA-derived eicosanoids are little explored, but a recent study found an increase in $\mathrm{PGE}_{3}$ in the sunburn response, which followed a similar time course to $\mathrm{PGE}_{2}$, with elevation at $4 \mathrm{~h}$ through to $72 \mathrm{~h}$ post-UVR (81). Omega-3 PUFA LOX products may act in an analogous manner, reducing UVR-induced n-6 PUFA-derived chemoattractants that promote an inflammatory white cell influx into the skin, although this remains to be tested (81). Reports regarding the effects of EPA on UVR-induced pro-inflammatory cytokines have been mixed, with in vitro studies in human skin cells showing a decrease in IL-8 (86) and by contrast a super-induction of IL- $1 \alpha$ and TNF- $\alpha$ (87), while a human study showed no effect on IL- $1 \beta$, IL-6, IL-8 and TNF- $\alpha$ (88).

A limited number of studies have addressed the potential of topically applied n-3 PUFA in UVR protection. Application of sardine oil (11.2\% EPA, $23.6 \%$ DHA) to human skin after UVB reduced erythema by $24.5 \%$ compared to control (89). However, topical ALA proved unsuccessful in reducing UV erythema, which may be explained by the lack of epidermal desaturase activity (10).

\section{Photosensitivity disorders}

Omega-3 PUFA may also protect against certain photosensitivity disorders, i.e. conditions in which patients show abnormal reactions to UVR. In an open study of 13 patients (two men, 11 women; median age 45, range 21-81 years) with the common photosensitivity disorder polymorphic light eruption, daily supplementation with $3 \mathrm{~g}$ mixed n-3 PUFA (1.8 g EPA + $1.2 \mathrm{~g}$ DHA) for 3 months resulted in a significant decrease in sensitivity to broadband UVA (313-370 $\mathrm{nm}$ ) papule provocation, in addition to an increase in the MED to UVB (3). In a small study of three children (all boys; ages 5-8 years) with the rare photosensitivity condition hydroa vacciniforme, supplementation with $1.5 \mathrm{~g}$ mixed EPA and DHA daily for 3 months resulted in all three children showing decreased erythemal sensitivity to UVA, with one child additionally showing decreased erythemal sensitivity to UVB. All three children also had a reduced response to lesion provocation by broadband UVA (5). The mechanisms underlying the protective effects are presently unknown, although the demonstrated reduction in UVB-induced $\mathrm{PGE}_{2}$ in the PLE study suggests that the n-3 PUFA may serve to reduce the pro-inflammatory 


\begin{tabular}{|c|c|c|}
\hline Clinical condition & Therapeutic potential indicated from in vivo intervention studies & References \\
\hline \multirow[t]{2}{*}{ Sunburn } & $\begin{array}{l}\text { Systemic and topical long-chain (LC) n-3 PUFA are reported to protect skin against acute } \\
\text { UVR-induced inflammation in humans }\end{array}$ & $(4,7,85,89)$ \\
\hline & $\begin{array}{l}\text { Systemic and topical LC and systemic short-chain n-3 PUFA are reported to protect } \\
\text { against UV inflammation in mice }\end{array}$ & $(8,10,45)$ \\
\hline Photosensitivity disorders & $\begin{array}{l}\text { Systemic LC n-3 PUFA are reported to increase the UVR threshold for provocation } \\
\text { of photosensitivity disorders including PLE }\end{array}$ & $(3,5)$ \\
\hline Photoageing & $\begin{array}{l}\text { Topical LC n-3 PUFA are reported to reduce histological and clinical signs of photoageing } \\
\text { in humans and histological signs of photoageing in mice }\end{array}$ & $(6,45)$ \\
\hline Photocarcinogenesis & $\begin{array}{l}\text { Systemic LC n-3 PUFA are reported to increase latency and reduce numbers of skin cancers in mice } \\
\text { Systemic and topical LC n-3 PUFA are reported to abrogate photoimmunosuppression in mice }\end{array}$ & $\begin{array}{l}(8,9,105) \\
(108-110)\end{array}$ \\
\hline
\end{tabular}

milieu. Controlled trials assessing protection from ambient UVR have not yet been reported in photosensitivity.

\section{Photoageing}

This is clinically observed as deep wrinkles, reduced elasticity and uneven pigmentation $(90,91)$, the former two changes attributed to remodelling of dermal connective tissue, i.e. the extracellular matrix (ECM), by matrix metalloproteinases (MMP). These endopeptidases are upregulated in response to UVR and can degrade many components of the skin's ECM including the major collagen and elastin networks (92-94). Both UVA and UVB are thought to increase MMP expression through generation of reactive oxygen species (95-97). However, recent work has identified that UVR may also have direct photochemical effects on components of the dermal ECM dependent on protein structure (98). Stressassociated p38 and c-Jun amino terminal kinase (JNK) are phosphorylated and activated by ROS, hence upregulating the more active form of AP-1, which can stimulate the induction of MMP-1 (the major collagenase in humans), MMP-2 (gelatinase-A) and MMP-3 (stromelysin) (99-101). Moreover, UVB is reported to stimulate MMP-1 and MMP-3 expression via the hydroxyl radical and lipid peroxidation products (93). Addition of EPA to irradiated dermal fibroblasts in vitro inhibits ERK and JNK activation, resulting in reduced c-Jun phosphorylation and decreased MMP expression (76). Similar results were observed in vivo in human skin, where topical EPA $(2 \% \mathrm{w} / \mathrm{v})$ inhibited expression of MMP-1 and MMP-9 (gelatinase-B) after UV irradiation, also through inhibition of $\mathrm{p} 38$ and JNK (6). $\mathrm{PGE}_{2}$ also induces MMP expression by macrophages and fibroblasts; modulating the balance of PG production towards the less inflammatory n-3 series may contribute to dampening of cellular responses and less damage to the surrounding ECM $(102,103)$. In addition to the prevention of ECM degradation, topical EPA is reported to promote expression of pro-collagen I and the elastic fibre components, tropoelastin and fibrillin-1 in intrinsically aged human skin through elevated TGF- $\beta$ signalling (6). Many of the effects discussed earlier may be mediated through modulation of oxidative stress by n-3 PUFA, these unstable fatty acids being speculated to act as an oxidisable buffer (4).

\section{Photocarcinogenesis}

Ultraviolet radiation is a complete carcinogen, both initiating the DNA damage that can lead to mutagenesis and promoting carcinogenesis through immunosuppression. Hairless mice fed corn oil rich in n-6 PUFA exhibited reduced latency and increased numbers of skin tumors after exposure to UVR, while in contrast, mice fed a diet supplemented with menhaden oil, rich in n-3
PUFA, exhibited increased latency and decreased tumor multiplicity $(8,104,105)$. Associations between PUFA ingestion and skin cancer have been observed in case-control studies in humans. Hakim et al. (106) found higher intakes of n-3 PUFA were associated with reduced risk of squamous cell carcinoma, and Kune et al. (107) observed an inverse relationship between fish consumption and risk of non-melanoma skin cancer.

Black et al. (105) suggested n-3 PUFA may act during the initiation phase of tumorigenesis, as when mice were changed from an n-6- to n-3 PUFA-rich diet post-UVR, tumor numbers did not reduce. However, evidence exists that n-3 PUFA exert protective effects at the tumor promotion stage through inhibition of photoimmunosuppression (108). Ability of n-3 PUFA to protect against both local and systemic UVR-induced immune suppression has been demonstrated in mice using the contact hypersensitivity response (CHS) model. Dietary EPA inhibited systemic immune suppression, resulting in a heightened CHS response to contact allergen trinitrochlorobenzene after UVB irradiation (109). In addition, topical EPA (98\% EPA ethyl ester) to murine skin reduced local UVB immune suppression, evidenced by increased response to difluoronitrobenzene compared to control oil (110). As $\mathrm{PGE}_{2}$ stimulates suppressor T-cell function, these results may be attributable to relatively reduced levels of $\mathrm{PGE}_{2}$ through increased synthesis of $\mathrm{PGE}_{3}$ from EPA (111). To date, effects of n-3 PUFA in abrogating photoimmunosuppression have not been reported in humans; such studies are currently ongoing in our laboratories.

Thus, systemic n-3 PUFA may provide an approach to protect against skin cancer, potentially including those prone individuals who are immunosuppressed following organ transplantation, although this remains to be tested (112).

\section{Safety profile}

In addition to beneficial effects it is important to consider any potential adverse effects associated with long-term n-3 PUFA supplementation. Several long-term studies have been performed examining the impact of n-3 PUFA supplements in healthy people and in those with coronary heart disease, liver disease and inflammatory bowel disease, with very few adverse effects observed, besides flatulence, halitosis and loose motions (113-117). However, certain subgroups of cardiac patients may respond less favourably, as seen in a study of patients with implantable cardioverter defibrillators (ICD), where fish oil appeared to be proarrythmic (118). It has also been suggested that cosupplementation of n-3 PUFA with antioxidants may be necessary to counteract potential increases in oxidative stress as a result of n-3 PUFA peroxidation; whereas this seems reasonable, it is not 
certain, and little is actually known regarding the appropriate ingested n-3 PUFA/antioxidant balance in humans (7,119-121).

\section{Advancing the understanding of $n-3$ PUFA biology}

Application of novel experimental approaches including nutrigenomics and lipidomics is anticipated to provide valuable insights into the exact roles of n-3 PUFA, including their influence on UV-irradiated skin cells. Nutrigenomics offers examination of the influence of nutrients on gene expression in health and disease. Integrated with nutrigenetic studies aiming to understand the impact of genetic variation on dietary response, and together with proteomic, metabolomic and lipidomic techniques, a more complete understanding of dietary regulation of molecular and cellular responses is becoming possible (122-126). This in turn may lead to identification of therapeutic targets in diet-related diseases and may ultimately aid development of dietary interventions based on specific nutritional requirements of individuals (127). Tools for studying genomic effects of nutrients are well established, including DNA microarrays and serial analysis of gene expression (SAGE), which allow expression of thousands of genes to be analysed simultaneously in small amounts of biological tissue/fluid. To date, few studies have utilised the microarray technique to examine the effects of PUFA on cell signalling and gene expression (128).

Lipidomics aims to provide full characterisation of lipid molecular species and their biological roles; this rapidly growing field is becoming an integral part of the multidisciplinary effort support- ing systems biology, molecular mechanisms of disease pathophysiology, biomarker discovery and drug development. Lipidomics is mass spectrometry based and has resulted in a range of potent and versatile analytical methodologies for many classes of biologically important lipids, in a variety of biological matrices (129131). The potential of this approach is exemplified in our recent reports revealing the contribution of different classes of eicosanoids to mediation of the sunburn response $(81,83,132)$.

\section{Conclusions}

Evidence suggests that LC n-3 PUFA, particularly EPA, are capable of reducing UV-induced inflammation in human skin, in addition to potentially offering protection against photoimmunosuppression, photocarcinogenesis, photoageing and photosensitivity disorders. Ultimately, combined dietary and standard topical sunscreen measures may optimise human skin protection from sunlight. The photoprotective properties of SC n-3 PUFA are less explored but may hold potential for skin protection.

Integrated analytical approaches such as microarrays in parallel with lipidomic analyses will help elucidate the numerous pathways through which n-3 PUFA regulate cellular processes and ultimately protect human skin health.

\section{Acknowledgements}

We acknowledge the Association for International Cancer Research (LER, AN) and the Biotechnology and Biological Sciences Research Council and Croda UK (SMP) for supporting this work.

\section{References}

1 Pilkington S M, Rhodes L E. Omega-3 fatty acids and skin. in: Nutrition for Healthy Skin: Strategies for Cosmetic and Clinical Practice. Krutmann J, Humbert $P$ (eds). Springer, Heidlberg/New York, 2010.

2 Cancer Research UK. Latest UK Cancer Incidence and Mortality Summary-Rates. http://info.cancer researchuk.org Accessed Nov 2010

3 Rhodes L E, Durham B H, Fraser W D et al. J Invest Dermatol 1995: 105: 532-535.

4 Rhodes $\mathrm{L}$ E, O'Farrell $\mathrm{S}$, Jackson $\mathrm{M}$ J et al. J Invest Dermatol 1994: 103: 151-154.

5 Rhodes L E, White S I. Br J Dermatol 1998: 138 173-178.

$6 \mathrm{Kim} \mathrm{H} \mathrm{H}$, Cho S, Lee $\mathrm{S}$ et al. J Lipid Res 2006 47: $921-930$

7 Rhodes L E, Shahbakhti H, Azurdia R M et al. Carcinogenesis 2003: 24: 919-925.

8 Orengo I F, Black H S, Kettler A H et al. Photochem Photobiol 1989: 49: 71-77.

9 Black H S, Rhodes L E. Cancer Detect Prev 2006: 30: 224-232

10 Takemura N, Takahashi K, Tanaka H et al. Photochem Photobiol 2002: 76: 657-663.

11 Norval M, Lucas R M, Cullen A P et al. Photochem Photobiol Sci 2011: 10: 199-225.

12 Diffey B. Phys Med Biol 2004: 49: R1-R11.

13 Sun Smart. Sun Protection. http://www.sun smart.com.au. Accessed Nov 2010.

14 Skin Cancer Foundation. http://www.skincancer org. Accessed Nov 2010

15 Health Canada. Sun and UV. http://www cancer.ca. Accessed Nov 2010.

16 Cancer Research UK. Sun Smart. http://www. sunsmart.org.uk. Accessed Nov 2010

17 Diffey B. BMJ 2000: 320: 176-177.

18 Bech-Thomsen $\mathrm{N}$, Wulf $\mathrm{H}$ C. Photodermatol Photoimmunol Photomed 1992: 9: 242-244.

19 Adam R, Magdalena H, Marta B et al. Photodermatol Photoimmunol Photomed 2009: 25: 242244.

20 Autier P, Dore J-F, Negrier S et al. J Natl Cancer Inst 1999: 91: 1304-1309.

21 Diffey B L. J Cosmet Dermatol 2002: 1: 124
22 Ling T C, Faulkner C, Rhodes L E. Photodermatol Photoimmunol Photomed 2003: 19: 98-101.

23 Sies H. Stahl W. Annu Rev Nutr 2004: 24: 173200.

24 Whelan J, Rust C. Annu Rev Nutr 2006: 26: 75103.

25 Verger $\mathrm{P}$, Khalfi $\mathrm{N}$, Roy $\mathrm{C}$ et al. Food Addit Contam Part A 2008: 25: 765-771.

26 Storelli M M. Food Chem Toxicol 2008: 46 2782-2788.

27 Miller M R, Nichols P D, Carter C G. Nutr Res Rev 2008: 21: 85-96.

28 Robert S S, Singh S P, Zhou $X$ et al. Funct Plant Biol 2005: 32: 473-479

29 Robert S, Petrie J, Zhou X-R et al. Mar Biotechnol 2009: 11: 410-418.

30 Simopoulos A. Asia Pacific J Clin Nutr 2002: 11: S163-S173.

31 Guil-Guerrero L J. Eur J Lipid Sci Tech 2007: 109 1226-1236.

32 Biooriginal. BioMega SDA. http://www.bio original.com. Accessed Nov 2010.

33 Ursin V M. J Nutr 2003: 133: 4271-4274.

34 Marriott H, Buttriss J. Nutr Bull 2002: 28: 355363.

35 Astorg P, Arnault N, Czernichow S et al. Lipids 2004: 39: 527-535

36 Simopoulos A P. Poult Sci 2000: 79: 961-970.

37 Chapkin R S, Ziboh V A, Marcelo C L et al. J Lipid Res 1986: 27: 945-954.

38 Pawlosky R J, Hibbeln J R, Novotny J A et al. J Lipid Res 2001: 42: 1257-1265.

39 Brenna J T. Curr Opin Clin Nutr Metab Care 2002: 5: 127-132.

40 Tang C, Cho H P, Nakamura M T et al. J Lipid Res 2003: 44: 686-695.

41 Fu Z, Sinclair A J. Pediatr Res 2000: 47: 414417.

42 James $\mathrm{M}$ J, Ursin V M, Cleland L G. Am J Clin Nutr 2003: 77: 1140-1145.

43 Yamazaki K, Fujikawa M, Hamazaki T et al. Biochim Biophys Acta 1992: 1123: 18-26.

$44 \mathrm{Kim}$ E, Kim M, Jin $X$ et al. J Korean Med Sci 2010: 25: 980-983.
45 Jin X J, Kim E J, Oh I K et al. J Korean Med Sci 2010: 25: 930-937.

46 Gresham A, Masferrer J, Chen X et al. Am J Physiol 1996: 270: C1037-C1050.

47 Balsinde J, Winstead M V, Dennis E A. FEBS Lett 2002: 531: 2-6.

48 Ziboh V A, Lord J T. Biochem J 1979: 184: 283290.

49 Ziboh V A, Miller C C, Cho Y. Am J Clin Nutr 2000: 71: 361S-366S

50 Nugteren $\mathrm{D} \mathrm{H}$, Christ-Hazelhof $\mathrm{E}$, van der Beek A et al. Biochim Biophys Acta 1985: 834: 429-436.

51 Ziboh V A. Proc Soc Exp Biol Med 1994: 205: $1-11$.

52 Lee J L, Mukhtar H, Bickers D R et al. Toxicol Appl Pharmacol 2003: 192: 294-306.

53 Lands W E. FASEB J 1992: 6: 2530-2536.

54 Powell W S, Gravel S, Gravelle F. J Lipid Res 1995: 36: 2590-2598.

55 Goldman D W, Pickett W C, Goetzl E J. Biochem Biophys Res Commun 1983: 117: 282-288.

56 Bagga D, Wang L, Farias-Eisner R et al. Proc Natl Acad Sci USA 2003: 100: 1751-1756.

57 Miller C C, Tang W, Ziboh V A et al. J Invest Dermatol 1991: 96: 98-103.

58 Fer M, Corcos L, Dreano $Y$ et al. J Lipid Res 2008: 49: 2379-2389.

59 Lapillonne A, Clarke S D, Heird W C. Curr Opin Clin Nutr Metab Care 2004: 7: 151-156.

60 Deckelbaum R J, Worgall T S, Seo T. Am J Clin Nutr 2006: 83: S1520-S1525.

61 Konger R L, Martel K C, Jernigan D et al. PPAR Res 2010: 2010: 467053.

62 Davies S S, Pontsler A V, Marathe G K et al. J Biol Chem 2001: 276: 16015-16023.

63 Chêne G, Dubourdeau M, Balard P et al. Biochim Biophys Acta 2007: 1771: 576-589.

64 Kippenberger S, Loitsch S M GrundmannKollmann $\mathrm{M}$ et al. 2001: 117: 1430-1436.

65 Fisher G J, Datta S C, Talwar H S et al. Nature 1996: 379: 335-339.

66 van den Berg $R$, Haenen $G$ R, van den Berg $H$ et al. Br J Nutr 2001: 86 (Suppl 1): S121-S127. 
67 Saliou C, Rimbach G, Moini H et al. Free Radic Biol Med 2001: 30: 154-160.

68 Seitz C S, Lin Q, Deng $\mathrm{H}$ et al. Proc Natl Acad Sci U SA 1998: 95: 2307-2312.

69 Novak T E, Babcock T A, Jho D H et al. Am J Physiol Lung Cell Mol Physiol 2003: 284: 84-89.

70 Takahashi M, Tsuboyama-Kasaoka N, Nakatani T et al. Am J Physiol 2002: 282: G338-G348.

71 Camera E, Mastrofrancesco A, Fabbri $C$ et al. Exp Dermatol 2009: 18: 222-231.

72 Warmuth I, Harth Y, Matsui M S et al. Cancer Res 1994: 54: 374-376.

73 Fisher G J, Talwar H S, Lin J et al. J Clin Invest 1998: 101: 1432-1440.

74 Angel P, Karin M. Biochim Biophys Acta 1991 1072: 129-157.

75 Liu G, Bibus D M, Bode A $M$ et al. Proc Nat Acad Sci USA 2001: 98: 7510-7515.

76 Kim H H, Shin C M, Park C H et al. J Lipid Res 2005: 46: 1712-1720.

77 Gilchrest B A, Soter N A, Hawk J L et al. J Am Acad Dermatol 1983: 9: 213-219.

78 Hawk J L, Murphy G M, Holden C A. Br J Dermatol 1988: 118: 27-30.

79 Sheehan J M, Young A R. Photochem Photobio Sci 2002: 1: 365-377.

80 Tripp C S, Blomme E A, Chinn K S et al. J Invest Dermatol 2003: 121: 853-861.

81 Rhodes L E, Gledhill K, Masoodi M et al. FASEB J 2009: 23: 3947-3956.

82 Judson B L, Miyaki A, Kekatpure V D et al. Cancer Prev Res 2010: 3: 1104-1111.

83 Pilkington S M, Massey K, Watson R E B et al. Br J Dermatol 2010: 163: 943

84 Rhodes L E, Belgi G, Parslew R et al. J Invest Dermatol 2001: 117: 880-885.

85 Orengo I F, Black H S, Wolf J E. Arch Dermatol Res 1992: 284: 219-221.

86 Storey A, McArdle F, Friedmann P S et al. J Invest Dermatol 2005: 124: 248-255.

87 Pupe A, Moison R, De Haes P et al. J Invest Dermatol 2002: 118: 692-698.

88 Shahbakhti H, Watson R E, Azurdia R M et al. Photochem Photobiol 2004: 80: 231-235.
89 Puglia C, Tropea S, Rizza L et al. Int J Pharm 2005: 299: 41-48.

90 Leyden J J. Br J Dermatol 1990: 122 (Suppl 35) $1-3$.

91 Berneburg M, Plettenberg H, Krutmann J. Photodermatol Photoimmunol Photomed 2000: 16 239-244.

92 Ashworth J L, Murphy G, Rock M J et al. Biochem J 1999: 340: 171-181.

93 Brenneisen P, Wenk J, Klotz L O et al. J Biol Chem 1998: 273: 5279-5287.

94 Scharffetter-Kochanek K, Wlaschek M, Hogg A et al. Arch Dermatol Res 1991: 283: 506-511.

95 Wlaschek M, Briviba K, Stricklin G P et al. J Invest Dermatol 1995: 104: 194-198.

96 Scharffetter-Kochanek K, Wlaschek M, Briviba K et al. FEBS Lett 1993: 331: 304-306.

97 Wenk J, Brenneisen $\mathrm{P}$, Wlaschek $\mathrm{M}$ et al. J Biol Chem 1999: 274: 25869-25876

98 Sherratt $M$ J, Bayley C P, Reilly S M et al. J Pathol 2010: 222: 32-40.

99 Herrmann G, Wlaschek M, Lange T S et al. Exp Dermatol 1993: 2: 92-97

100 Herrmann G, Wlaschek M, Bolsen $\mathrm{K}$ et al. J Invest Dermatol 1996: 107: 398-403.

101 Klotz L O, Pellieux C, Briviba K et al. Eur J Biochem 1999: 260: 917-922.

102 Mauviel A, Halcin C, Vasiloudes P et al. J Cell Biochem 1994: 54: 465-472.

103 Pentland A P, Shapiro S D, Welgus H G. J Invest Dermatol 1995: 104: 52-57.

104 Reeve V E, Bosnic M, Boehm-Wilcox C. Cancer Lett 1996: 108: 271-279

105 Black H S, Thornby J I, Gerguis J et al. Photochem Photobiol 1992: 56: 195-199.

106 Hakim I A, Harris R B, Ritenbaugh C. Nutr Cancer 2000: 36: 155-162.

107 Kune G A, Bannerman S, Field B et al. Nutr Cancer 1992: 18: 237-244.

108 Fischer M A, Black H S. Photochem Photobiol 1991: 54: 381-387.

109 Moison R M, Beijersbergen Van Henegouwen G M. Radiat Res 2001: 156: 36-44.
110 Moison R M, Steenvoorden D P, Beijersbergen van Henegouwen G M. Photochem Photobiol 2001: 73: 64-70.

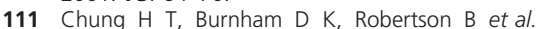
J Immunol 1986: 137: 2478-2484.

112 Hofbauer G F, Bouwes Bavinck J N, Euvrard S. Exp Dermatol 2010: 19: 473-482.

113 Capanni M, Calella F, Biagini M R et al. Aliment Pharmacol Ther 2006: 23: 1143-1151.

114 Saynor R, Gillott T. Lipids 1992: 27: 533-538.

115 Eritsland J, Arnesen H, Seljeflot I et al. Am J Clin Nutr 1995: 61: 831-836.

116 Belluzzi A. Proc Nutr Soc 2002: 61: 391-395.

117 Durrington $P$ N, Bhatnagar D, Mackness M । et al. Heart 2001: 85: 544-548.

118 Raitt $\mathrm{M} \mathrm{H}$, Connor W E, Morris $\mathrm{C}$ et al. JAMA 2005: 293: 2884-2891.

119 Meydani M, Natiello F, Goldin B et al. J Nutr 1991: 121: 484-491

120 Anttolainen M, Valsta L M, Alfthan G et al. Eur J Clin Nutr 1996: 50: 741-746.

121 Freese R, Dragsted L O, Loft $S$ et al. Eur J Clin Nutr 2008: 62: 1151-1153.

122 Kaput J. Curr Opin Biotechnol 2008: 19: 110120.

123 Kussmann M. Expert Rev Proteomics 2009: 6 453-456.

124 Whitfield P D, German A J, Noble P J. Br J Nutr 2004: 92: 549-555.

125 German J B, Gillies L A, Smilowitz J T et al. Curr Opin Lipidol 2007: 18: 66-71.

126 German J B, Roberts M A, Fay L et al. J Nutr 2002: 132: 2486-2487.

127 Simopoulos A P. Annu Rev Public Health 2010: 31: $53-68$.

128 Narayanan B A, Narayanan N K, Reddy B S. Int J Oncol 2001: 19: 1255-1262.

129 van Meer G. EMBO J 2005: 24: 3159-3165.

130 Masoodi M, Mir A A, Petasis N A et al. Rapid Commun Mass Spectrom 2008: 22: 75-83.

131 Masoodi M, Nicolaou A. Rapid Commun Mass Spectrom 2006: 20: 3023-3029.

132 Nicolaou A, Pilkington S M, Rhodes L E. Chem Phys Lipids 2011, in press. 